\title{
Visualizing the Dynamic Shorelands of the Great Lakes
}

MARÍA ARQUERO DE ALARCÓN (CORRESPONDING AUTHOR)

Associate Professor of Architecture and Urban and Regional Planning, A. Alfred Taubman

College of Architecture \& Urban Planning, 2000 Bonisteel Boulevard, University of

Michigan, Ann Arbor, MI 48109

marquero@umich.edu

JENNIFER MAIGRET

Associate Professor of Architecture, A. Alfred Taubman College of Architecture \& Urban

Planning, 2000 Bonisteel Boulevard, University of Michigan, Ann Arbor, MI 48109

SUSAN LANDFRIED

Research Assistant (Master of Urban Planning, 2016), A. Alfred Taubman College of Architecture \& Urban Planning, 2000 Bonisteel Boulevard, University of Michigan, Ann Arbor, MI 48109

BIN ZHANG

Research Assistant (Master of Architecture, 2015), A. Alfred Taubman College of Architecture \& Urban Planning, 2000 Bonisteel Boulevard, University of Michigan, Ann Arbor, MI 48109

Volume 4, 2016

http://dx.doi.org/10.3998/mjs.12333712.0004.005

\section{ABSTRACT}

The shorelands of the Great Lakes are dynamic systems that shape the culture, economy, and ecology of the region. The 3,200+ miles of Michigan shorelands support one-third of the state's cities and border four Great Lakes. This territory provides a rich inventory of waterfront conditions that will experience exacerbated conditions of change as future climate conditions amplify current fluctuations. This littoral zone is always in flux. Lake water levels register seasonal to decadal temporal oscillations 
and are amplified by strong and tall waves. These interactions pose acute challenges to lakeshore communities when negotiating between the necessity for setback regulations and their desire for access and proximity to the water. Given this context, sustainable planning efforts for shorelands must strategically accommodate dynamic fluctuations balanced with efforts for protection, enjoyment, and development.

This article displays a series of visualization techniques depicting shoreland dynamics along Lake Michigan, as part of a research collaboration funded by the Graham Sustainability Institute's Water Center at the University of Michigan. The initiative draws upon expertise in coastal hydrodynamics, land use and environmental planning, fiscal analysis, vulnerability assessment, and visualization, and it partners with Land Information Access Association (LIAA), a Michigan nonprofit that assists communities in developing resilience planning strategies. As a collaborative research tool, visualization provides a platform for synthesis and enables more engaged and enlightened conversations with local communities, stakeholders, and decision-makers.

\section{Visualization as a platform for communication}

Revealing the dynamic nature of water is the first step toward planning for more resilient waterfront communities. This is especially critical in circumstances where allowable waterfront development is set by the definition of the water's extent and governed by the ordinarily high water elevation mark (Norton, Meadows and Meadows, 2013). Herein lies a fundamental challenge for communities seeking to balance environmental foresight, the right of public access to the water, and economic stability. This article describes the role that visualization techniques can play when integrated in coordination with quantitative research methods and community engagement and outreach efforts. In particular, the authors contend that the use of technically "simple" techniques, which can be described in a manual and which municipalities or community groups can independently apply, can make a profound contribution as a component of holistic resilience planning.

Visualization is a tool of data display, data synthesis and spatial thinking with the capacity to represent competing interests for debate. Methodologically, visualization techniques can be structured to facilitate collaborative, interdisciplinary research by integrating disparate areas of expertise and communicating complex sets of information with precision and clarity. Furthermore, visualization techniques can 

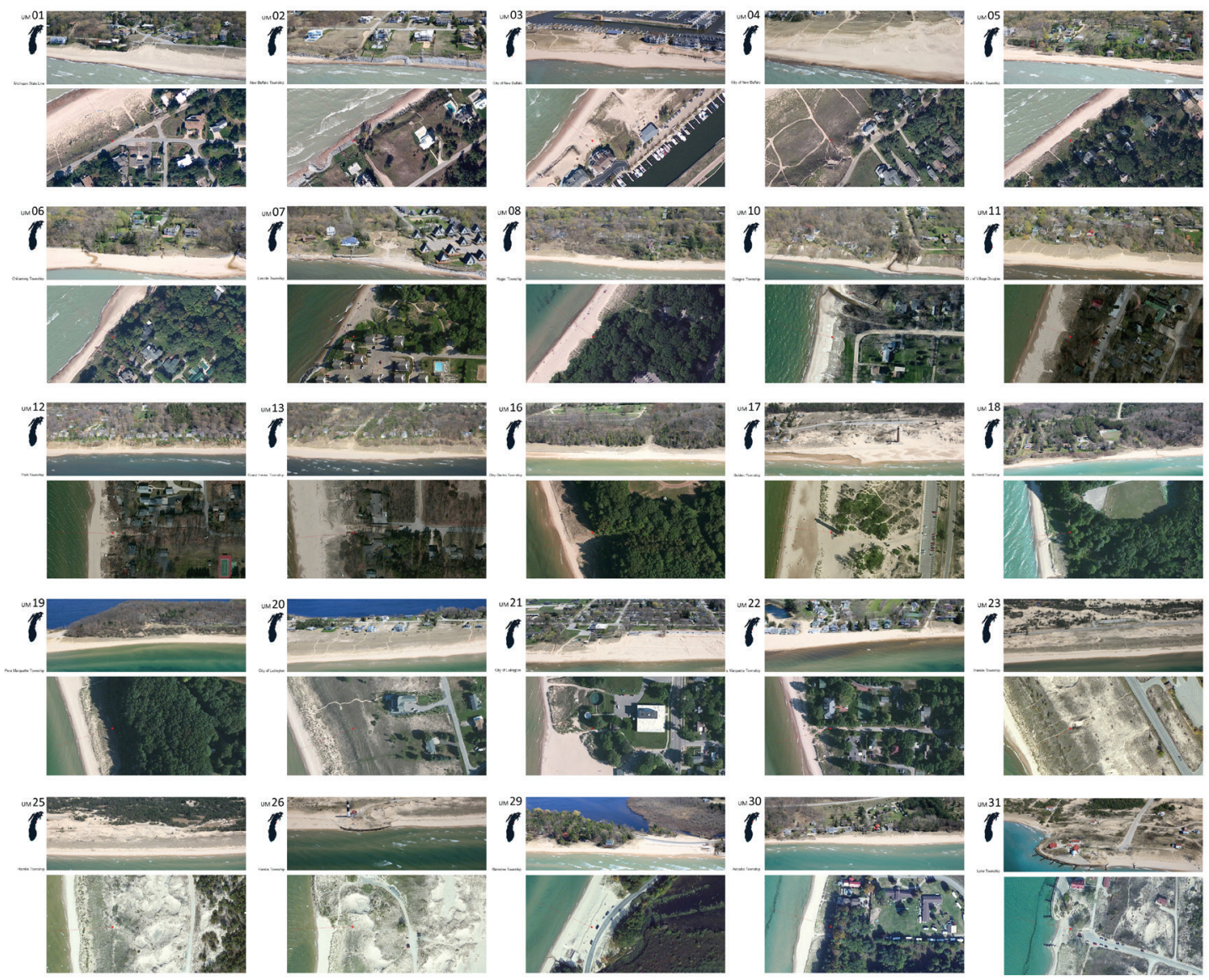

Figure 1. Shoreland landscapes along Lake Michigan

Lake Michigan aerial images at the 26 survey sites following the study of lake level dynamics conducted by Meadows and Meadows. The surveys track water and land dynamics on the different sites over decades.

Image Sources: Bird's eye views from USACE - http://greatlakes.usace.army.mil/ and Google Earth for the aerial images.

foster more productive interactions between academic, professional practice, and community engagement efforts. Outcomes derived from the use of visualization tools in public participation initiatives, intending to sustainably manage landscape change, are well documented in the literature of the planning and design disciplines (Lange 2011, Schroth et al. 2011, Hayek, 2011). These initiatives evaluate their effectiveness to communicate existing conditions and patterns of change, and to speculate on future trends through the development of scenarios.

The assessment of effectiveness, for any given combination of visualization techniques, is intimately linked to the specific composition of each audience, and is 


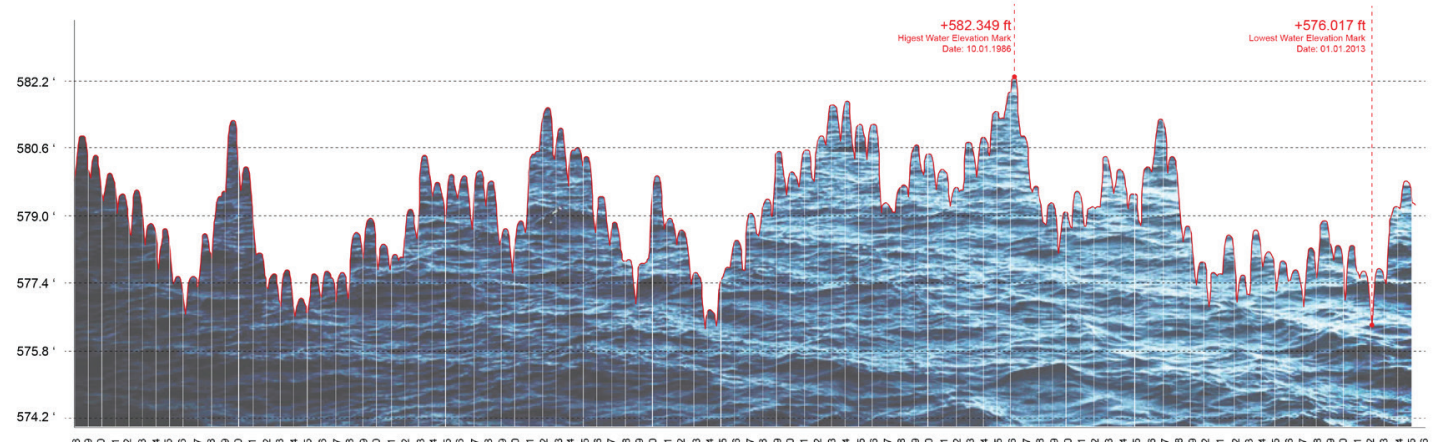

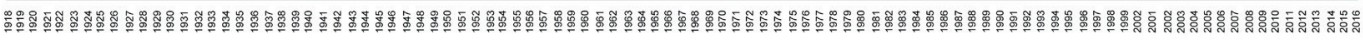

Figure 2. Lake Michigan monthly average water levels, 1938-2013

While Lake Michigan has been experiencing relatively low average water levels for the past decade, lake levels register cyclical changes with decadal or even longer intervals that tend to escape the memory of the residents. The graph represents the Michigan Lake water elevations from 1938 to 2015, highlighting the highest and lowest elevation marks in 1986 and 2013, respectively.

Source: NOAA Great Lakes Water Level Dashboard: http://www.glerl.noaa.gov/data/dashboard/GLWLD.html

Andrew D. Gronewold, Anne H. Clites, Joeseph P. Smith, and Timothy S. Hunter. A dynamic graphical interface for visualizing projected, measured, and reconstructed surface water elevations on the earth's largest lakes. Environmental Modeling \& Software, Volume 49, November 2013, pages 34-39: http://dx.doi.org/10.1016/j.envsoft.2013.07.003.

therefore an evolving process. The range of techniques this paper describes reflects many considerations specific to our collaborative process and the feedback offered by various Michigan coastal communities, research team members, LIAA staff, and local stakeholders. Concurrently, the development of multi-scalar cartographies and aerial overlays informed the research design and raised awareness among community members about the need for more stringent controls in the permit processes along the shoreland. At the center of this transdisciplinary (Stokols 2006) research approach, visualization offers a platform for the continuous negotiation of goals and agendas among participants and for the integration of applied knowledge to expand communities' capacity to comprehend the dynamic manifestations of shorelands through geographical and temporal scales.

\section{Engaging Uncertainty: Tracing futures}

The research framework leverages scenario planning to consider a range of variations and amplifications in seasonal, decadal, and multi-decadal oscillations in 


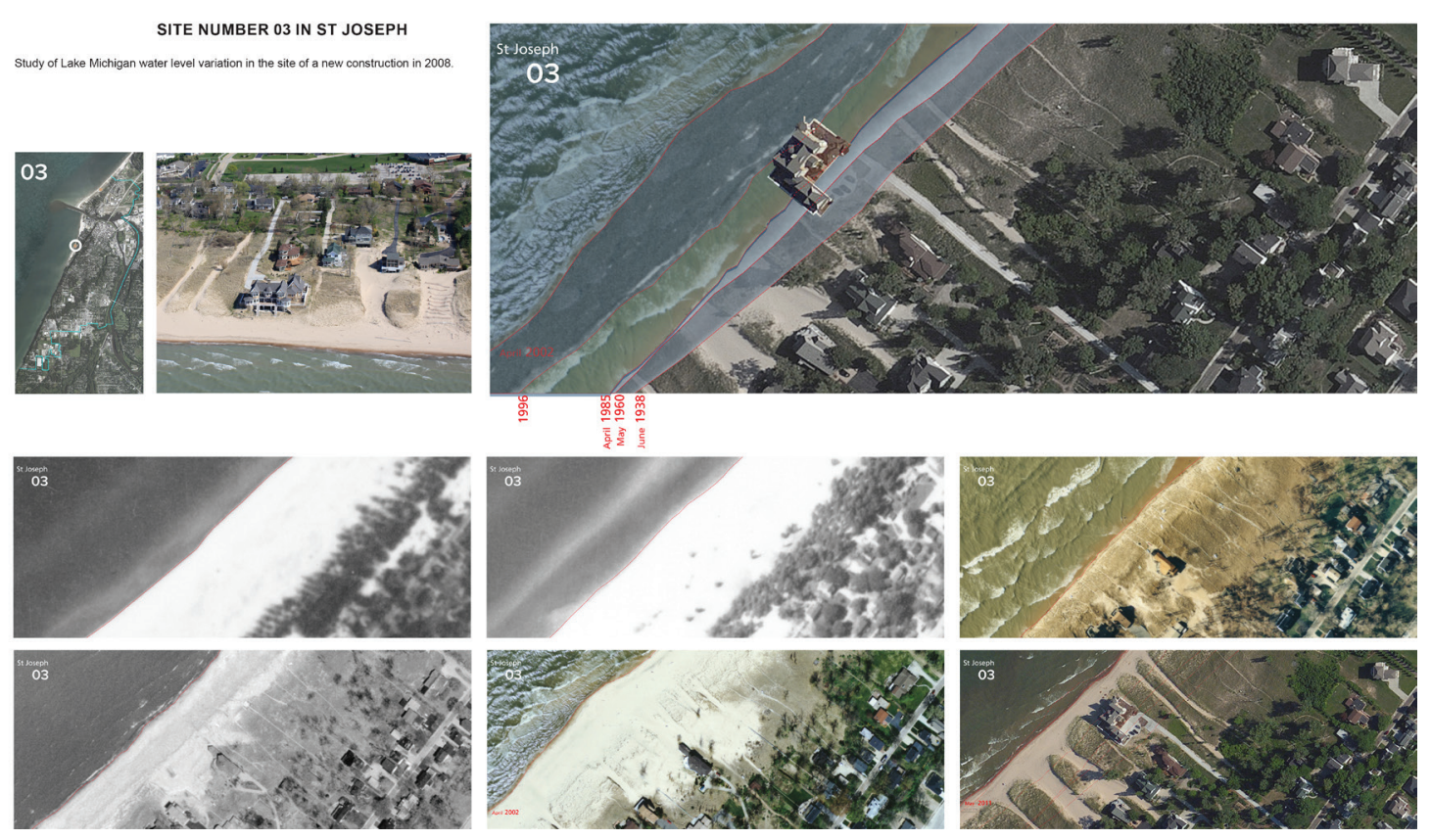

Figure 3. The changing shoreline in St. Joseph, Michigan

The comparison of aerial images from the years 1938 to 2012 illustrate the fluctuating shoreline, and the recent construction of property in the site. The composite image overlays the shorelines from 1938, 1960, 1985, 1997, and 2002 on the 2008 image, the year of the mansion's construction. Responding to the recent high lake water levels in 2015 , the newly built house has now been relocated further back on the parcel to prevent recurring flooding.

Great Lakes water levels (Meadows et al. 1997). Environmental, fiscal, and land use conditions are assessed relative to three climate future scenarios: "lucky," "expected," and "perfect storm." These scenarios shed light on a more detailed understanding of the trade-offs that a community may confront when weighing municipal growth management options against flooding risks. The visualization of these possible futures enables debate over and integration of variable and/or competing ideas toward the development and adoption of resilience planning strategies. By engaging uncertainty through defined terms, visualizations facilitate dialogue and consensus building.

Each scenario incorporates relevant components from FEMA's Great Lakes Coastal Flood Study and FEMA's Flood Insurance Rate Maps (FIRM) along with long-term decadal patterns of lake level fluctuations. The details defining each scenario are as follows: 


\section{SITE TRANSECT STUDIES}
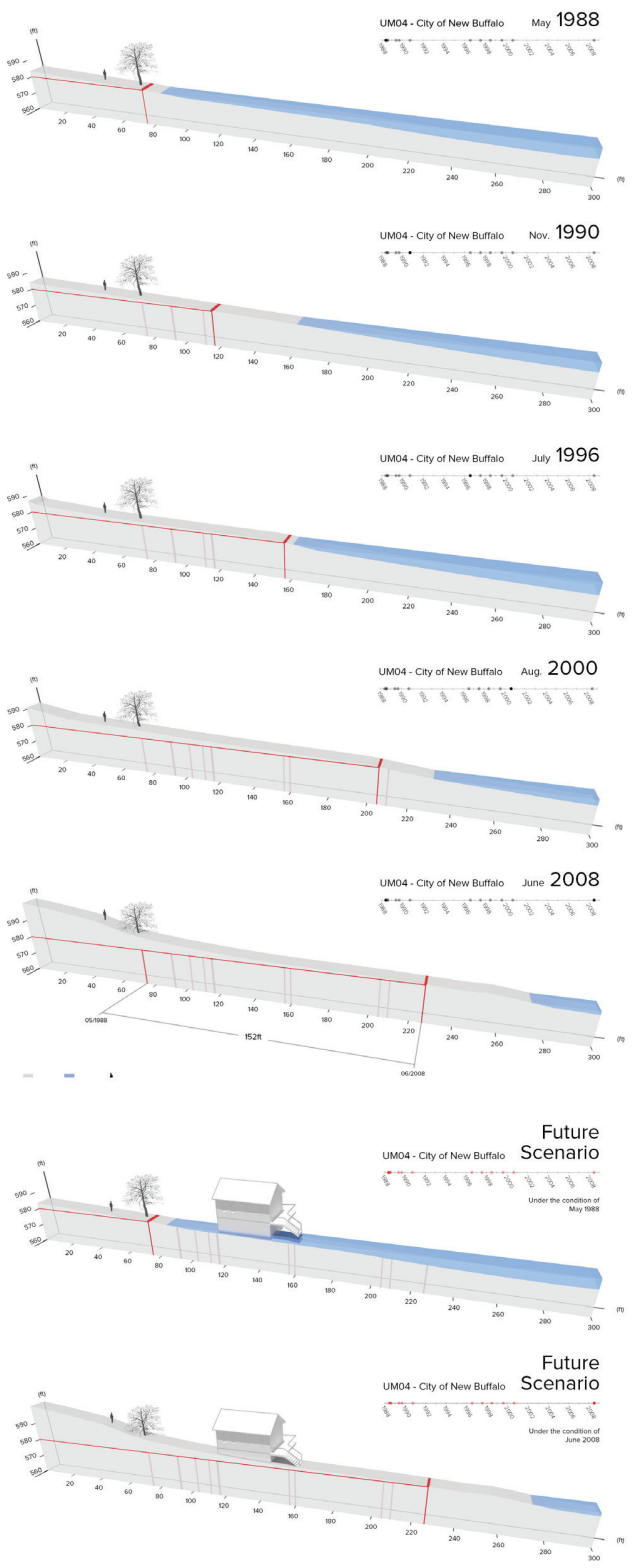

Land Water Height=6ft - Ordinary High Water Elevation 580.5ft

Figure 4. Video and animation still frames with site survey transects in the city of Ludington.

Through a mix of representation techniques that include animations, archival imagery, and contemporary photographic sources, the video visualizes coastal dynamics and property at risk, challenging the current definition of the ordinary high water elevation mark (OHWM) as a mechanism to safely manage construction practices along the shorelands. In so doing, it contributes to ongoing efforts to raise public awareness concerning the need to transform coastal management practices. 

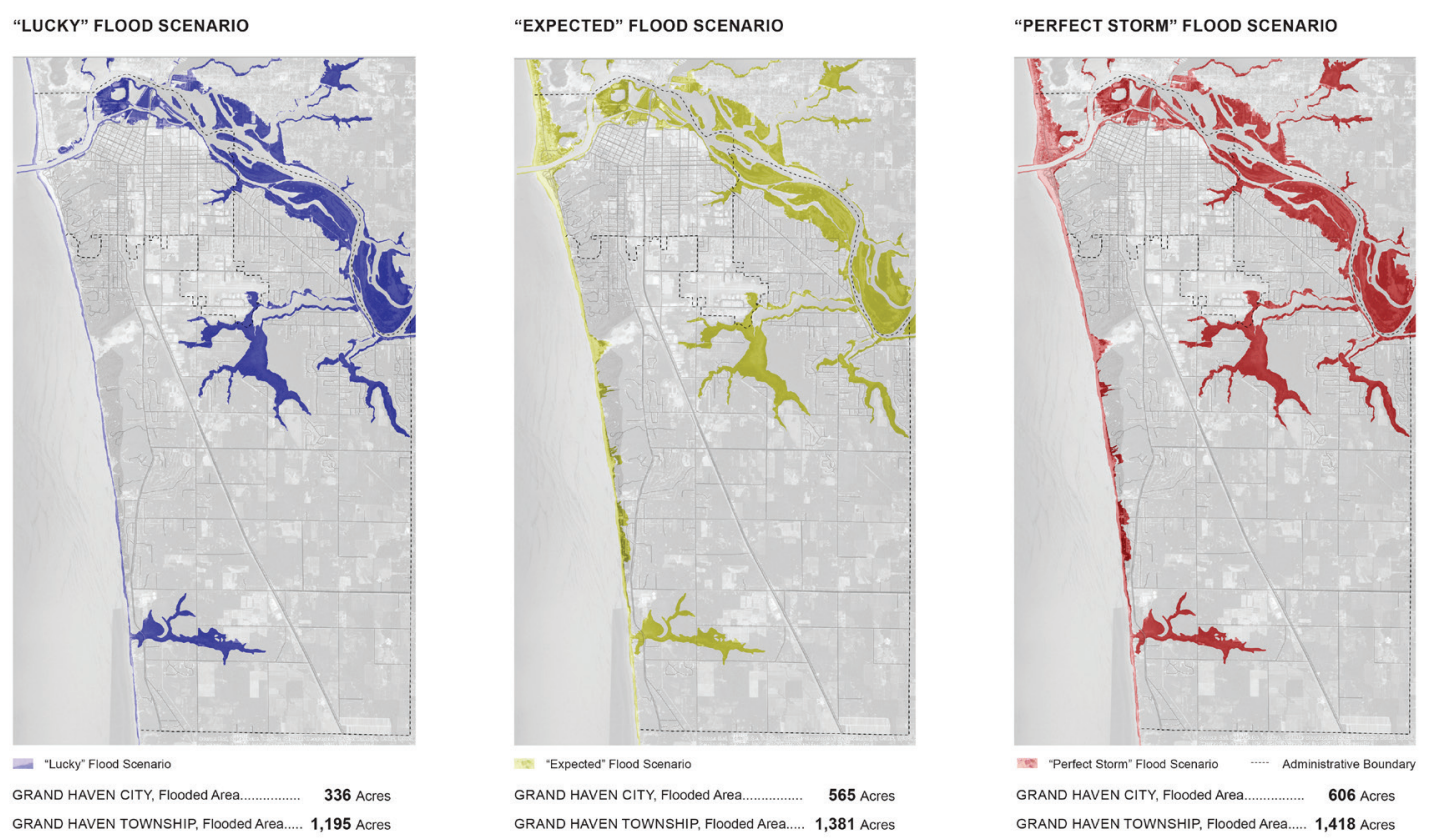

Figure 5. Maps of the City and Township of Grand Haven illustrating the three potential flooding scenarios: "Lucky (blue), Expected (light green), and Perfect Storm (dark red)." Through a scenarioplanning framework, the research assesses the environmental, fiscal, and land-use conditions under different climate futures that focus on rising levels of flooding and local government management options. Each image highlights the acres affected by flooding in both the City and the Township of Grand Haven.

- The "Lucky" flood scenario assumes that Great Lakes water levels will remain low. Although there will be wave and wind action, major storm events and wave impacts will not encroach on properties landward of current beaches. Potentially flooded inland areas will remain as currently delineated by FEMA under effective FIRMs. Other climactic conditions like storm frequency and intensity and heat waves will remain consistent with patterns in recent history

- In the "Expected" flood scenario, Great Lakes water levels will continue to fluctuate according to long-term decadal patterns with water elevation close to the long-term average (580 feet). There will also be more frequent large storm events. During these high water periods, a 100-year storm event will create waves that will encroach on properties while areas more likely to experience strong winds and high waves (high velocity wave (VE zone)) will be completely destroyed. Portions of the community in the will also be severely damaged by inundation.

- The "Perfect Storm" flood scenario builds upon the assumptions of the "Ex- 
PARCELS AFFECTED UNDER THE "PERFECT STORM” FLOOD SCENARIO

\begin{tabular}{|c|c|c|}
\hline 37 & & 37 \\
\hline 112 & $\infty$ & 112 \\
\hline 02 & & 02 \\
\hline 197 & $\frac{\sigma}{\alpha} \frac{0}{\alpha}$ & 201 \\
\hline 46 & 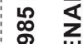 & 46 \\
\hline 31 & $\succeq$ U. & 53 \\
\hline 04 & z & 99 \\
\hline & $\underset{\mathrm{J}}{\mathrm{W}}$ & 72 \\
\hline 60 & \begin{tabular}{ll}
$I$ & \multicolumn{1}{c}{} \\
& $\vdots$
\end{tabular} & 60 \\
\hline 24 & v & 24 \\
\hline & & 25 \\
\hline 154 & 폰 & 156 \\
\hline 01 & 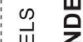 & 01 \\
\hline 19 & $\begin{array}{ll}0 \\
\frac{\alpha}{\alpha} & 3 \\
\end{array}$ & 22 \\
\hline 03 & 崩 & 03 \\
\hline 37 & $\cong \quad \frac{w}{4}$ & 37 \\
\hline 303 & $\begin{array}{ll}I & \varangle \\
O N & 0\end{array}$ & 523 \\
\hline 279 & 斈 & 279 \\
\hline 40 & 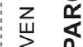 & 40 \\
\hline 01 & $\begin{array}{l}\text { 禾 } \\
0\end{array}$ & 01 \\
\hline 15 & $\underset{\substack{z\\
}}{z}$ & 15 \\
\hline 02 & 0 & 03 \\
\hline
\end{tabular}
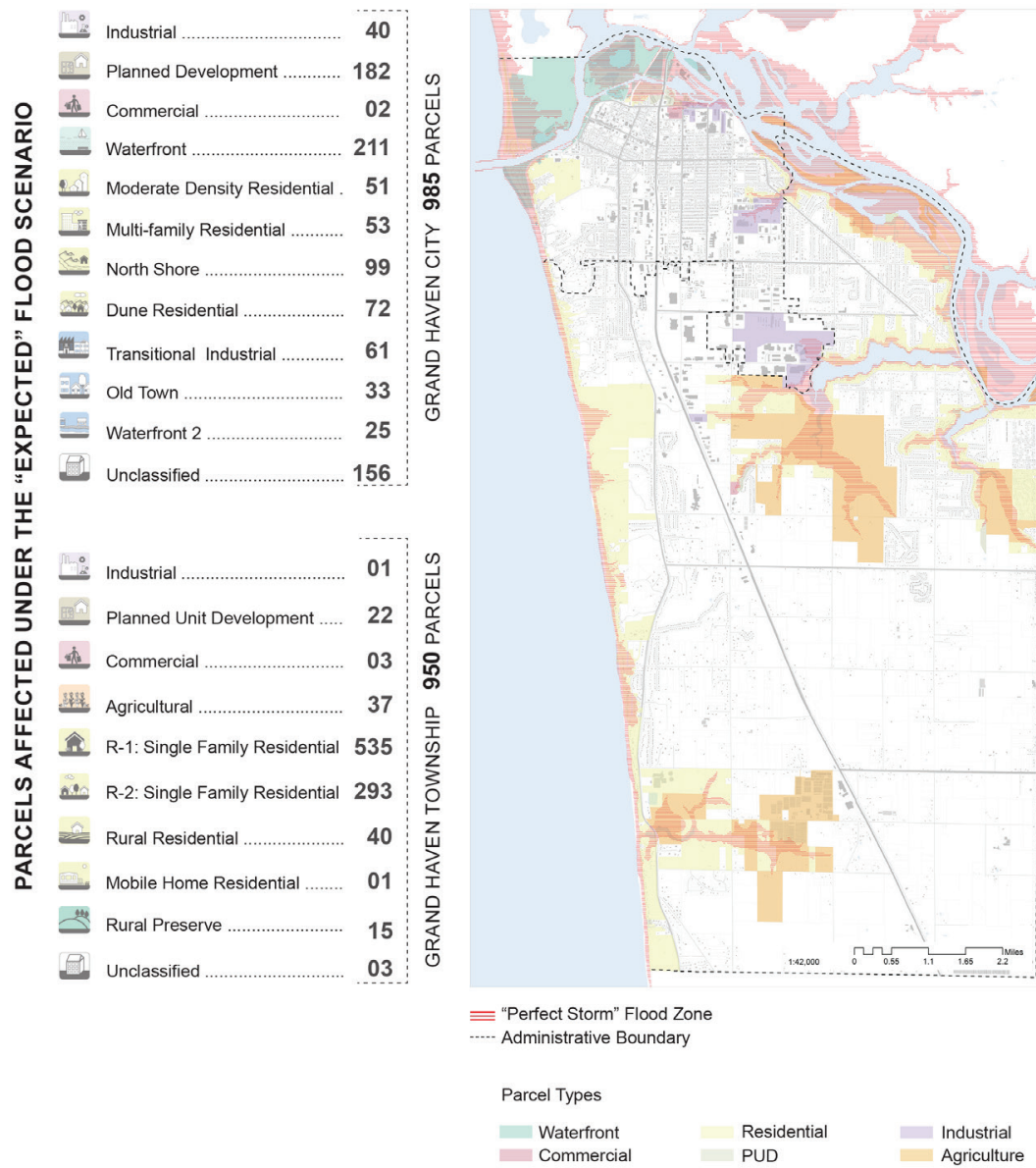

Figure 6. Map of the City and Township of Grand Haven illustrating the impacted land uses in the "Perfect Storm" scenario. The accompanying figures show the number of parcels per land-use impacted by flooding in both the city and the township in each of the three scenarios, for easy comparison.

pected" future. As a difference, Great Lakes still water elevation will be closer to the long-term high (583 feet) than the average high (580 feet). Additionally, because of increased frequency and intensity of storms, the shoreland areas are subject to VE zone conditions as well as more frequent inundation and severe property damage.

The three climate future scenarios serve as frameworks to evaluate variables controlled by municipal planning. One such example is the evaluation of possible management options available to local governments. Here, the research considers 

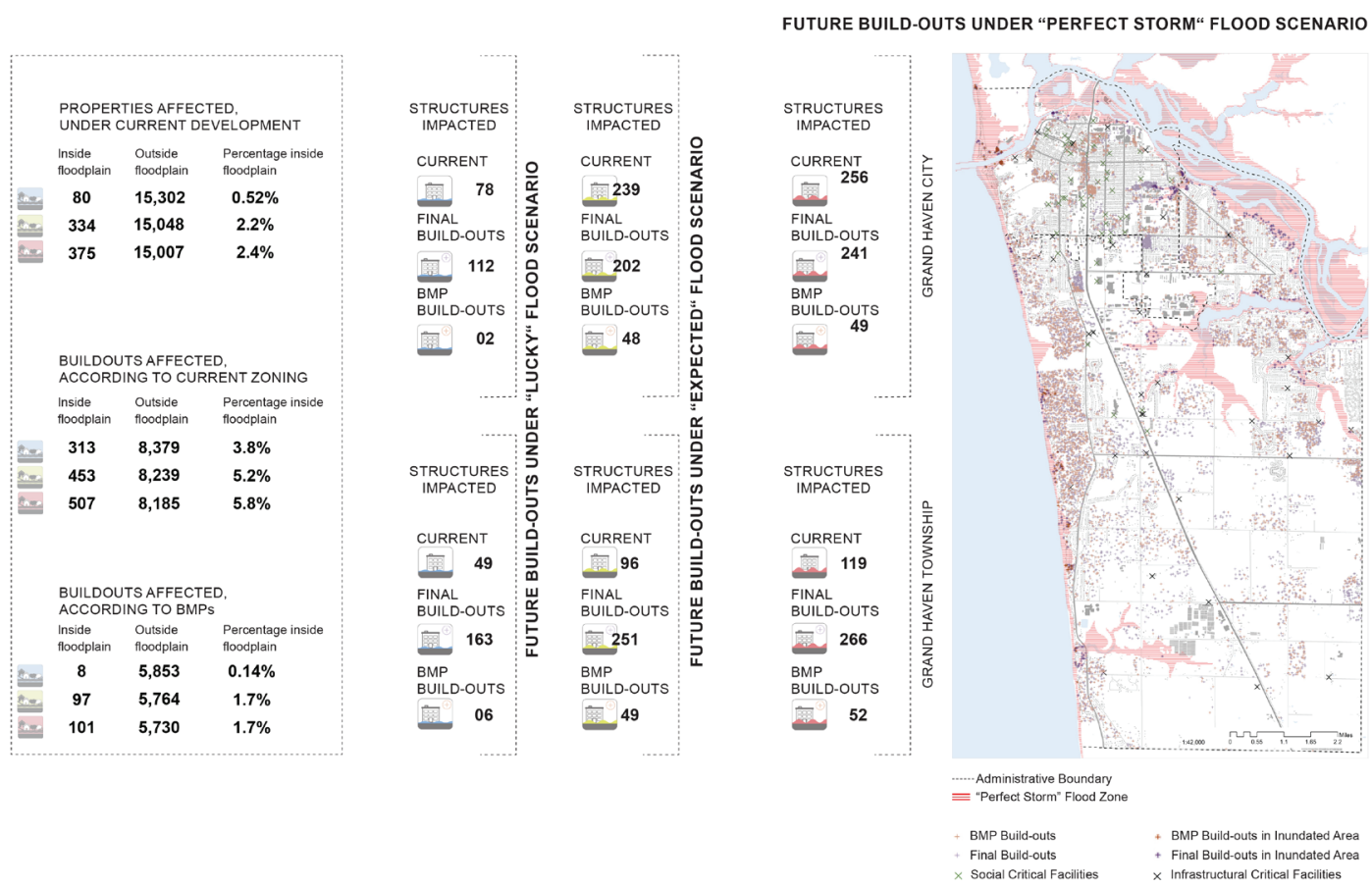

Figure 7. Maps of the City and Township of Grand Haven illustrating the number of potentially flood-impacted structures in the "Perfect Storm" scenario. The data displayed considers municipal management under current conditions, maximizing future build-out, and following BMP build-out. The accompanying figures show the number of flood-impacted structures in both the city and the township in each of the three scenarios, for easy comparison.

the existing condition and two future build-out options evaluated within each of the three climate frameworks. These build-outs range from continuing patterns of new development in accordance with current zoning ordinances and master plans (final build-outs) to establishing build-outs in accordance with best management practices (BMP) for coastal areas. Both scenarios assume that 60 percent of the maximum potential build-out would occur in order to account for new infrastructure including roads and sidewalks. The scenarios also assume that final build-outs can occur in all areas, as dictated by the zoning code, except on bodies of water, current buildings and roads, and publicly owned parcels. BMP build-outs follow these limitations and additionally restrict development from occurring within 50 feet of an inland water source, wetlands of at least five acres, and in any currently designated wetlands.

Lastly, a series of maps display the overlay of future scenarios and build-outs with the different environmental features in the area: tree canopy, wetlands, highrisk erosion areas, and critical dunes. 


\section{CRITICAL DUNES, HREA AND BUILD-OUTS \\ UNDER FUTURE FLOOD SCENARIOS}

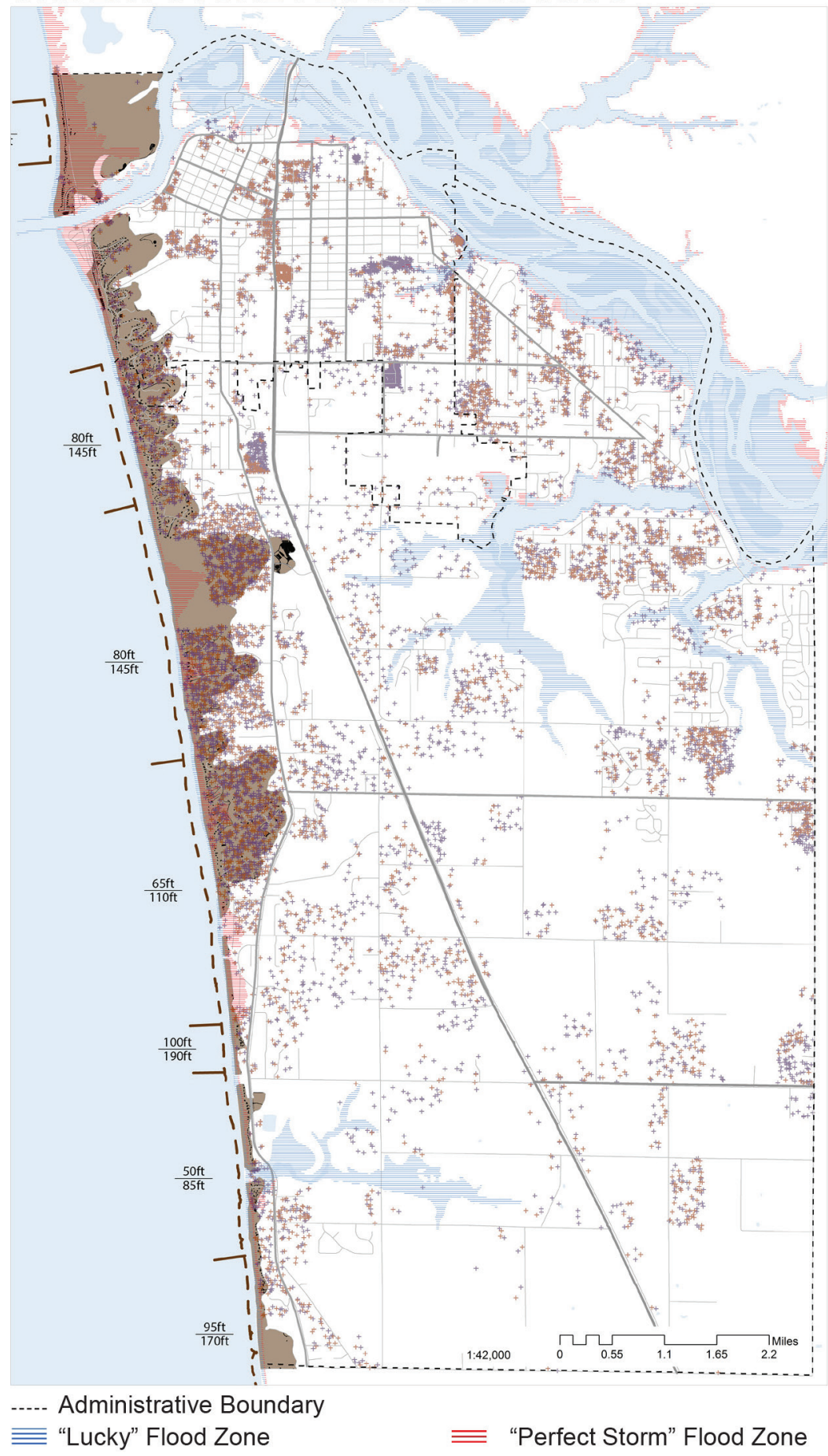

Critical Dunes

--- Offset Line Illustrating the Extend of the Shoreline Affected

Recession Distances: ft: 30 year projection / ft: 60 year projection

* BMP Build-outs in Critical Dunes

Final Build-outs

* Final Build-outs in Critical Dunes

BMP Build-outs

Figure 8. Overlay maps of the City and Township of Grand Haven showing the three potential flooding scenarios and build-outs, and their relationship to critical dunes and high-risk erosion areas.

This image visualizes the impacts that future construction will impose on critical environmental features if regulations continue to allow development in critical dunes in Michigan coastal communities. 


\section{SITE ATLAS OF COASTAL SITES}
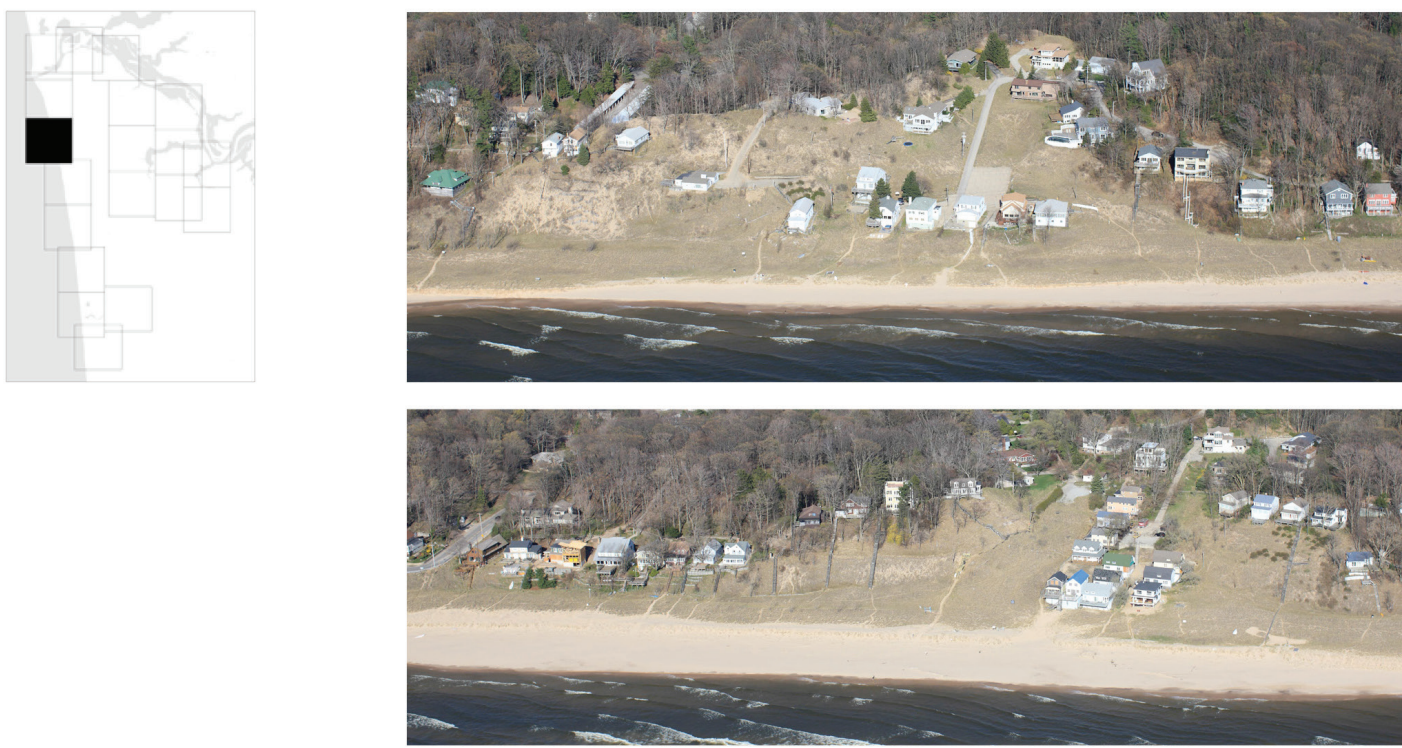

Bird's Eye View

2015

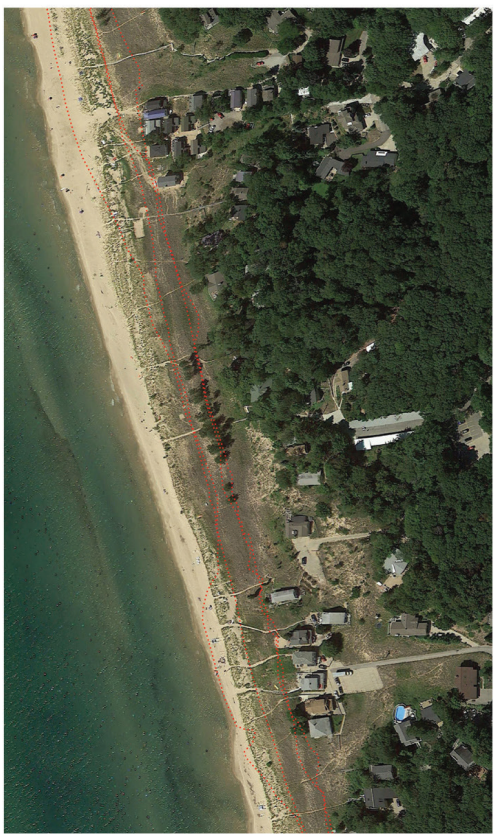

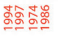

1974

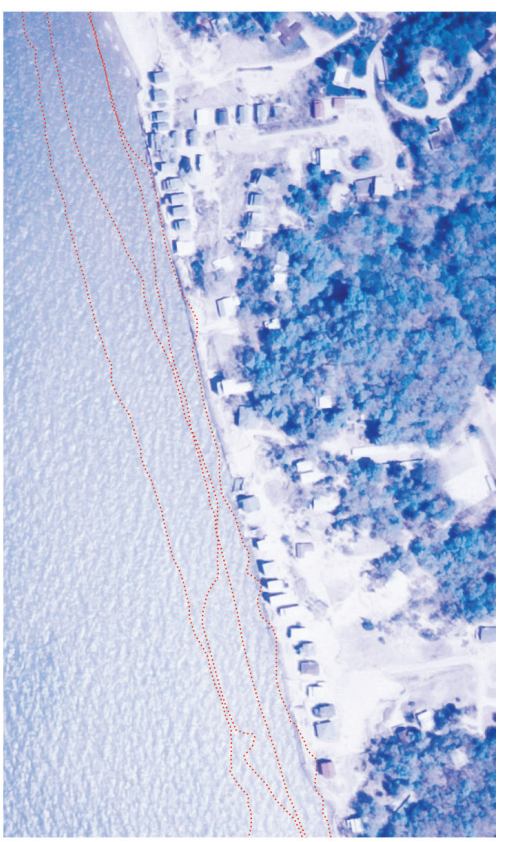

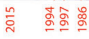

Figure 9. A close-up view of Grand Haven's shoreline

The use of historical and contemporary aerial images complements the information conveyed by the maps and enhances the viewer's site awareness and connection to a place. In the aerial images, the viewer can easily track where houses have disappeared between 1974 and 2015, enabling a more nuanced discussion of what the inevitably changing shoreland means. 

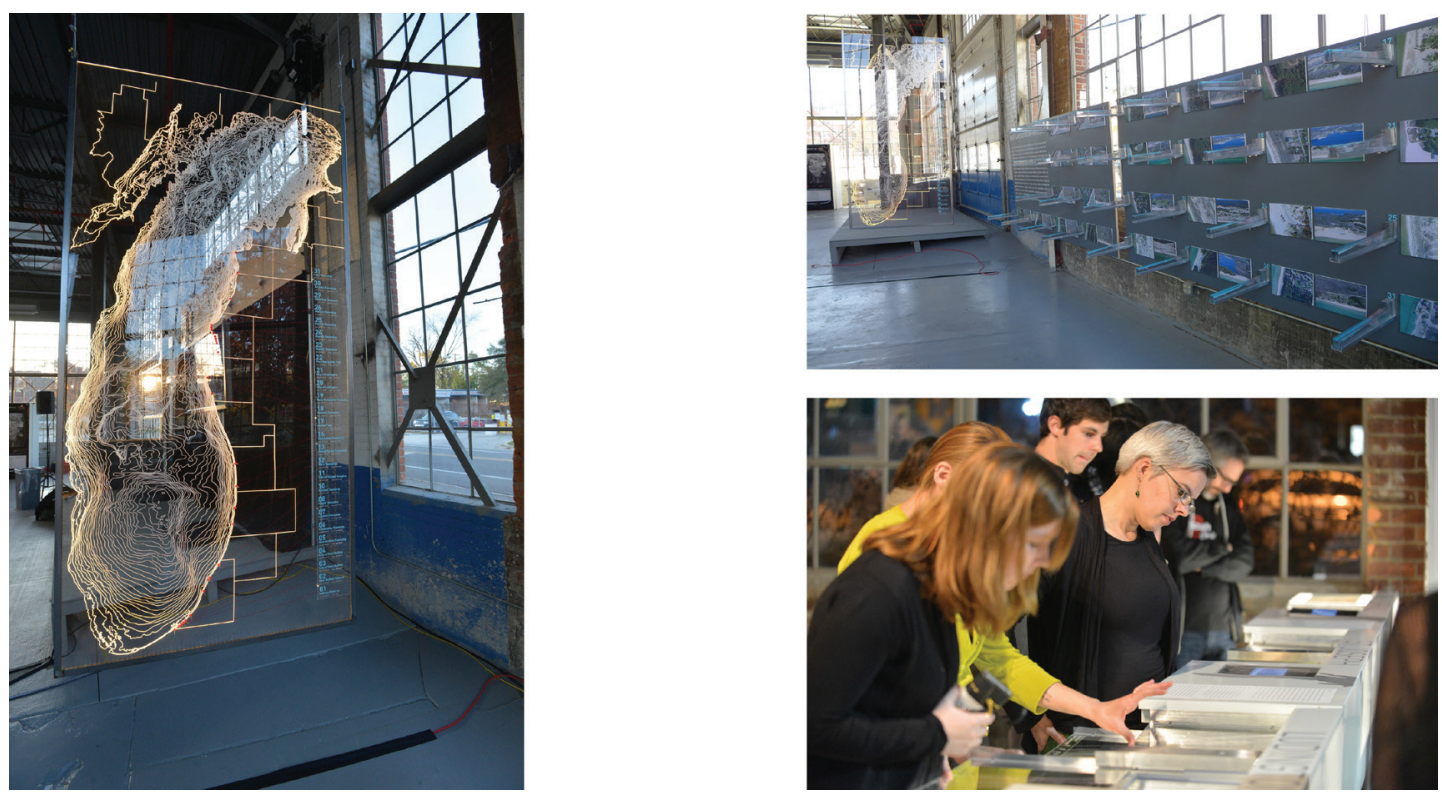

Figure 10. Images from the Research on the City Exhibition

Visualization's ability to render complex dynamics in comprehensible, familiar, and appealing ways engages the public to think about the implications of planning for uncertainty. The exhibition included three main components: a large map of Lake Michigan with the location of the 26 surveyed sites, a larger board with the transect studies and the aerial and birds eye view in each site, and a table displaying historical aerial images and videos for three sites: the Michigan coastal cities of Ludington, St. Joseph, and New Buffalo.

\section{Conclusion}

Using representation techniques including animations, archival imagery, contemporary photographic sources, and cartographies of coastal dynamics, this investigation contributes to ongoing efforts to raise public awareness of the need to transform coastal management practices. As a tool of documentation and data display, visualization allows for the negotiation and integration of otherwise discrete disciplinary contributions. This fosters the potential to reveal spatial patterns and management possibilities that may not be evident if considered in isolation. Furthermore, these practices facilitate the integration of different and/or competing ideas, promote dialogues, and enable consensus building. In each of these ways, community decisions are informed by the careful consideration of past and present conditions. Similarly, the ability to consider trade-offs in relationship to planning decisions is a necessary step when establishing desirable, shared visions of more sustainable futures. Ultimately, visual representation reveals spatial conflicts and potentials, enables criti- 
cal and imaginative interventions, and anticipates future planning and projective capacities.

\section{Acknowledgments}

The work illustrated in this article has been sponsored through two grants:

Taubman College Research on the City Grant, the University of Michigan, 2013

"Great Lakes Cities on the Shore: Representing Complex Shoreline Dynamics for Policy Making”

Team Members: María Arquero de Alarcón, Jennifer Maigret, and Richard Norton (Taubman College), and Lorelle Meadows (College of Engineering). Research Assistants: Wen Zhong, Andrew Wolking, John Guinn, Anna Schaefferkoeter, and Le Nguyen.

Water Center, the University of Michigan, 2013-2015

"Restoring, Retrofitting, and Recoupling Michigan's Great Lakes Shorelands"

Principal Investigators: Richard K. Norton Land Use and Environmental Policy) and Joe VanderMeulen (LIAA)

Project Managment: Stephen Buckman (Post-Doctoral Research Associate), and Zachary Rable (Taubman College Research Associate).

Visualization Component: María Arquero de Alarcón and Jennifer Maigret, assisted by graduate students Susan Landfried, Bin Zhang, and Wen Zhong (Taubman College).

Financial Component: David Bieri and Lan Deng

Coastal Hydrology Component: Guy and Lorelle Meadows, Hydrological Dynamics, Michigan Technological University, and Paul WebbSchool of Natural Resources and the Environment

Community Engagement Component: Claire Karner, Katie Sieb, LIAA.

Governmental Partners: R. Wuycheck and A. Gonzales, Michigan Department of Environmental Quality, Office of the Great Lakes.

\section{References}

Hayek, Ulrike Wissen. 2011. "Which is the appropriate 3D visualization type for participatory landscape planning workshops? A portfolio of their effectiveness." Environment and Planning B: Planning and Design 38: 921-939. 
Lange, Eckart. 2011. "99 volumes later: We can visualize. Now what?' Landscape and Urban Planning 100: 403-406.

Meadows, G.A., L.A. Meadows, W.L.Wood, J.M. Hubertz, and M. Perlin. 1997. “The relationship between Great Lakes water levels, wave energies, and shoreline damage." Bulletin of the American Meteorological Society 78 (4): 675-683.

Norton, Richard K., Guy A. Meadows, and Lorelle A. Meadows. 2013. "The deceptively complicated "elevation ordinary high water mark" and the problem with using it on a Laurentian Great Lakes shore." Journal of Great Lakes Research 39: 527-535.

Schroth, Olaf, Ulrike Wissen Hayek, Eckart Lange, Stephen R.J. Sheppard, and Willy A. Schmid. 2011. "Multiple-Case study of landscape visualizations as a tool in transdisciplinary planning workshops." Landscape Journal: design, planning, and management of the land 30(1): 53-71.

Stokols, Daniel. 2006. "Toward a Science of Transdisciplinarity Action Research.” American Journal of Community Psychology 38: 63-77. 